\title{
Asymptomatic presentation of type A aortic dissection with complete right coronary artery avulsion: a case report.
}

\author{
Andriy Dralov ${ }^{1}$ and Aldo Milano ${ }^{2}$ \\ ${ }^{1}$ Università degli Studi di Verona \\ ${ }^{2}$ Università degli Studi di Bari Aldo Moro
}

September 22, 2020

\begin{abstract}
Acute aortic dissection is the most challenging, life-threatening condition and requires prompt diagnosis and management. However about one-third of patients with type A acute aortic dissection (TAAAD) die within 24 hours, $50 \%$ within 48 hours and $95 \%$ die within first month. [1] Futhermore aortic dissection complicate with malperfusion syndrome is a devastating condition. Acute myocardial infarction within the TAAAD is the most fatal situation and occurs in about $1-2 \%$ of cases.[2] A total coronary artery avulsion is somewhat rare event in setting of TAAAD specially when it's asymptomatic. the authors describe a case of a young man who underwent aortic root surgery and aortic arch replacemente for aortic type A dissectioc with complete right coronary artery avulsion completely asintomatic at presentation.
\end{abstract}

\section{Asymptomatic presentation of type A aortic dissection with complete right coronary artery avulsion: a case report.}

Andriy Dralov MD ${ }^{1}$, Senior Resident at Cardiovascular and Thoracic Surgery Unit, ${ }^{1}$ Depertment of Cardiovascular and Thoracic Surgery, Cardiac Surgery Unit, University Hospital of Verona. Resident at Cardiac Surgery Unit, University Hospital of Bari.

Aldo D. Milano, MD, PhD; Professor of Cardiac Surgery, Director of cardiac Surgery Unit, University of Bari Medical School, Department of Emergency and Organ Transplantats.

All authors gave substantial contribution to study and interpretation of data, revised the paper and approved the final version.

Corresponding author: Andriy Dralov, Department of Cardiovascular and Thoracic Surgery, Cardiac Surgery Unit, University Hospital of Verona, P. le Aristide Stefani 1, 37126 Verona, Italy; Email address : andriydralogmail.com; Tel.: +39 32008209 65; fax :+39080 5592037.

\section{Introduction}

Acute aortic dissection is the most challenging, life-threatening condition and requires prompt diagnosis and management. However about one-third of patients with type A acute aortic dissection (TAAAD) die within 24 hours, $50 \%$ within 48 hours and $95 \%$ die within first month. [1] Acute myocardial infarction within the TAAAD is the most fatal situation and occurs in about 1-2\% of cases.[2] A total coronary artery avulsion is somewhat rare event in setting of TAAAD specially when it's asymptomatic. TAAAD occurs at a rate of 3-4 per 100,000 per year [3] and a delay in diagnosis, after symptomatic onset, leads to increase mortality in order of $1 \%$ to $2 \%$ per hour of misdiagnosed presentation of acute type A aortic dissection. [4] Coronary artery malperfusion has an incidence of 6-19\%. [5-8] In about $25 \%$ of patients the acute aortic syndrome occur with acute coronary syndrome ( ACS ) and sometimes is misdiagnosed and treated not propery. [9] Moreover patients with acute coronary involvement have an higher incidence of aortic regurgitation. 
Together, aortic regurgitation and coronary artery malperfusion may lead to acute ventricular failure.[2,9] The standard approach to treat patients with aortic root and arch dissection remain the open surgical approach by hypothermic circulatory arrest and cerebral perfusion.[10] We report a case of a young patient, treated 3-years ago for acute type B aortic disseection who underwent cardiac surgery for sub-acute type A aortic dissection ( De Backey type I, Stanford type A) and discuss the features of this case.

\section{Material and Methods}

We retrospectively evaluated clinical outcome, presentation and surgical technique to understand whether if it was possible an another surgical approach or further diagnostic investigation to uncover a coronary disease. The study was performed in the University Hospital of Bari, Italy and were approved by the Ethical Committee of the hospital. Written informed consent was obtained from the patient. All scientific literature were obtained from medical databases.

A 35-year old man was referred to our unit for evaluation of new onset of type A aortic dissection evidenced at CT scan in a follow up program. The patient was affected by type B acute aortic dissection treated on February 2016 with percutaneous fenestration of the false lumen. The dissection ( De Bakey type III) started from thoracic descending aorta, with the intimal flap within the left subclavian artery and re-entery flap involving the iliac bifurcation. The celiac axis, the superior mesenteric artery with both renal arteries result from the false lumen. Futhermore, the origin of celiac axis and mesenteric artery were obstructed by the intimal flap with signs of incipient abdominal ischemia. These conditions were treated by fenestration of the false lumen and apposition of two stents on the origins of the arteries respectively. At control angiography after the procedure, all the arteries were patent. After this procedure the patient was admitted and underwent follow up with regular CT scan (6 month). After almost 3 years, on December 2018, the patient came back to our institution with evidence of a Type A aortic dissection at CT scan. After an accurate interrogation the patient seems to have been affected by undefined feeling of chest pain once, some weeks before. The pain wasn't so intense as to arouse suspicion, even considering the previous presentation and meticulous counseling after the first aortic dissection and, in this way, probably was mistaken for muscular pain or even flu. So the patient decided to wait for the next scheduled CT scan check-up and after telling the story he was immediately sent to our unit. In order to clarify indications for surgery the patient underwent an preoperative echocardiography that confirmed normal left ventricular (LV) function with mild aortic regurgitation. The quality of CT scan was also good enought to show an haematoma/dissection round the right coronary ostium. The haematoma seemes to involve the coronary artery with preservation of intracoronary flow. ( Fig.1). Moreover, we were in possession of fenestration procedure performed near three years before with no signs of coronary artery disease. An preoperatory ECG was normal, as well as levels of troponines. No signs of diskinesia or akinesia were observed at 2D echocardiography but an imagine of intramural haematoma alongside the right coronary ostia. (Fig2).

\section{Results}

Facing on an sub-acute type A aortic dissection in 35-years old patient, after an accurate evaluation and discussion with patient, we decide to perform a complete aortic root, ascending aorta and aortic arch replacement. A classical sternotomy approach was performed with CPB in ipothermia at $22{ }^{\circ} \mathrm{C}$, deep circulatory arrest and selective cerebral perfusion. Arterial cannulation was performed on left common femoral artery. Myocardial protection was archived by infusion of retrograde cold blood intermittent cardioplegia. On aortic cross-clamp, after opening the ascending aorta we observed a circumferential dissection of the aorta and a complete avulsion of right coronary ostium dissected protruding about $1 \mathrm{~cm}$ into the right sinus of Valsalva. (Fig.3). The aortic valve was also affected. Right and non-coronary commissure were completely detached. Thus, a Tirone-David valve sparring procedure was performed. Ascending aorta was replaced with $28 \mathrm{~mm}$ prostetic conduit. Right coronary artery course was isolated ad obliterated within the proximal portion. Coronary artery bypass was also performed using great saphenous vein on right coronary artery and proximal anastomosis on aortic root. At $22{ }^{\circ} \mathrm{C}$, on circulatory arrest and cerebral perfusion we performed aortic acrh raplacemant with $26 \mathrm{~mm}$ vascular prothesis and the distal anastomosis on discending thoracic aorta with elephant-trunk technique. Reimplantation of epiaortic vessels was also obtained in open fascion by "island" 
technique. On $\mathrm{CPB}$, as rewarming, an anastomosis between the two vascular prosthesis was performed. CPB weaning wasn't really easy: the patient developed a right side post operatory dysfunction and required few days on inotropes during ICU stay. Anyway at discharge, the right side dysfunction was completely resolved with no residual regional dyskinesia. No aortic incompetence were noted. The patient also underwent a CT scan control at 1 month after the surgery that confirmed a good flow in aortic root and aortic arch.

\section{Conclusions}

Generally abrupt pain chest or back pain is the most common onset of TAAAD according to IRAD and so at presentation about $80 \%$ of patient experience pain. [5] An atypical presentation of aortic dissection makes the diagnosis difficult and thus is contributing to elevated mortality associated with this syndrome.[11,12] In this case epiaortic vessels were also involved likely without clinical manifestations. By definition, malperfusion describes signs and symptoms of end organ dysfunction due to low blood flow [13]. The inflammatory cascade related to end-organ dysfunction increase significantly surgical risk. [14,15] In this case we observed a total rupture of intima, media and adventitia about one centimeter from the ostium of right coronary artery. Non signs and symptoms of ischemia were documented. The characteristics of the hematoma suggest a recent formation compatible with the diagnosis of sub-acute dissection. If it is assumed that the onset was at the time of chest discomfort about 2 weeks earlier, several days have passed before the first medical contact and admission to our ICU.

Probably, consolidation of the hematoma and a progressive increase in the false lumen stretched the right coronary so as to allow complete detachment. At the same time, however, the flow was contained by the presence of the hematoma. The patient may have had a certain degree of ischemia or angina at dissection, not recognized at the time of admission.

Another hypothesis is the perioperative detachment compatible also with the presence of right-side postoperative dysfunction as well as use of retrograde cardioplegia. [16]

To our opinion, this is the first case of totally asymptomatic subacute type A aortic dissection with right artery avulsion at presentation described in literature. We also advise surgeons, in cases of aortic root involvement, to be always ready to an unplanned myocardial revascularization.

\section{Conflicted of interest: none}

Authors contribution: all authors gave substantial contribution to study. Critical revision of data and revision of article (Aldo D. Milano), data collection and revision of article (Andriy Dralov).

\section{References}

1. Demers P, Miller DC. Type A aortic dissection. In: Sellke FW, del Nido PJ, Swanson SJ, eds. Sabiston \& Spencer Surgery of the Chest (8th ed). Philadelphia, PA: Saunders Elsevier; 2010: 1089-114.

2. Braverman AC, Thompson RW, Sanchez LA. Diseases of the aorta. In: Bonow RO, Mann DL, Zipes DP, Libby P, Eds. Braunwald's Heart Disease: A Textbook of Cardiovascular Medicine. 9th ed. Philadelphia: Saunders Elsevier Inc. 2011: pp. 1309-37.

3. Ramanath VS, Oh JK, Sundt TM III, Eagle KA. Acute aortic syndrome and thoracic aortic aneurysm. Mayo Clin Proc 2009; 84: 465-81.

4. Arturo Evangelista, Eric M. Isselbacher,et al. Insights From the International Registry of Acute Aortic Dissection A 20-Year Experience of Collaborative Clinical Research Circulation. 2018;137:1846-1860.

5. Hagan PG, Nienaber CA, Isselbacher EM, et al . The International Registry of Acute Aortic Dissection (IRAD): New insights into an old disease. JAMA 2000; 283: 897-903.

6. Girdauskas E, Kuntze T, Borger MA, Falk V, Mohr FW. Surgical risk of preoperative malperfusion in acute type A aortic dissection. J Thorac Cardiovasc Surg 2009; 138: 1363-9.

7. Kawahito K, Adachi H, Murata S, Yamaguchi A, Ino T. Coronary malperfusion due to type A aortic dissection: Mechanism and surgical management. Ann Thorac Surg 2003; 76: 1471-6.

8. Neri E, Toscano T, Papalia U, et al . Proximal aortic dissection with coronary malperfusion: Presentation, management, and outcome. J Thorac Cardiovasc Surg 2001; 121: 552-60. 
9. Biagini E, Lofiego C, Ferlito M, et al . Frequency, determinants, and clinical relevance of acute coronary syndrome-like electrocardiographic findings in patients with acute aortic syndrome. Am J Cardiol 2007; 100: 1013-9.

10. 2014 ESC Guidelines on the diagnosis and treatment of aortic diseases Document covering acute and chronic aortic diseases of the thoracic and abdominal aorta of the adult The Task Force for the Diagnosis and Treatment of Aortic Diseases of the European Society of Cardiology (ESC) Authors/Task Force members: Raimund Erbel* (Chairperson) (Germany), Victor Aboyans* (Chairperson) (France), Catherine Boileau (France), Eduardo Bossone (Italy), Roberto Di Bartolomeo (Italy) et al. European Heart Journal (2014) 35, 2873-2926.

11. Gaul C, Dietrich W, Erbguth FJ. Neurological symptoms in aortic dissection: a challenge for neurologists. Cerebrovasc Dis 2008;26:1-8.

12. Kanjwal K, Karabin B, Kanjwal Y, et al. Differentiation of convulsive syncope from epilepsy with an implantable loop recorder. Int J Med Sci 2009;6:296-300.

13. Girdauskas E, Kuntze T, Borger MA, Falk V, Mohr F. Surgical risk of preoperative malperfusion in acute type A aortic dissection. J Thorac Cardiovasc Surg 2009; 138: 1363-9.

14. Girardi LN, Krieger KH, Lee LY, Mack CA, Tortolani AJ, Isom OW. Management strategies for type A dissection complicated by peripheral vascular malperfusion. Ann Thorac Surg 2004; 77: 1309-14.

15. Deeb GM, Williams DM, Bolling SF, et al . Surgical delay for acute type A dissection with malperfusion. Ann Thorac Surg 1997; 64: 1669-75.

16. Allen et al. Retrograde cardioplegia does not adequately perfuse the right ventricle The Journal of Thoracic and Cardiovascular Surgery Volume 109, Number 6 June 1995, Pages 1116-1126.

\section{Hosted file}

Figure 1.pdf available at https://authorea.com/users/360910/articles/482448-asymptomaticpresentation-of-type-a-aortic-dissection-with-complete-right-coronary-artery-avulsion-acase-report 